\title{
地方高校创建一流应用化学专业的探索与实践
}

许雪棠，周立亚，段文贵 ${ }^{*}$

广西大学化学化工学院, 南宁 530004

摘要: 广西大学应用化学专业历经20余年的建设, 已经形成了鲜明的地域特色和学科特色。全面介绍了本专业在专 业定位、师资队伍建设、基层教学组织、实验教学改革、协同育人建设、专业质量保障体系建设等方面的举措和成 效。

关键词: 专业建设; 应用化学; 地方高校; 探索与实践

中图分类号: G64; O6

\section{Exploration and Practice of Creating First-Class Applied Chemistry Major in Local Colleges and Universities}

Xuetang Xu, Liya Zhou, Wengui Duan *

School of Chemistry and Chemical Engineering, Guangxi University, Nanning 530004, China.

Abstract: After more than 20 years of construction, the applied chemistry major of Guangxi University has formed distinct regional and disciplinary characteristics. This paper comprehensively introduced the measures and achievements of this major in terms of professional positioning, faculty building, grassroots teaching organization, experimental teaching reform, construction of collaborative education, and construction of professional quality assurance system.

Key Words: Professional construction; Applied chemistry; Local college and university; Exploration and practice

2018年9月, 教育部发文, 要求加快建设高水平本科教育, 全面提高人才培养能力 ${ }^{[1]}$ 。2019年教 育部启动了一流本科专业建设 “双万计划” , 目的是通过一流专业建设, 带动高校优化专业结构、 促进专业建设质量提升、形成高水平人才培养体系, 实现高等教育内涵式发展, 全面振兴本科教育。

专业建设是高校教育质量的根本保证, 是学校发展的重要基础, 直接影响到学校发展的整体水 平、综合实力和社会声誉; 并直接关系到学校的办学特色与人才的质量规格, 决定着人才的竞争 力 ${ }^{[2]}$ 。要持续提升专业内涵和建设水平, 坚持需求导向、标准导向、特色导向, 以社会需求为前提, 以 一流专业标准为参照, 强化专业特色。

广西大学应用化学本科专业成立于1998年7月, 于同年9月开始招生, 学制四年, 授理学学士学 位。历经 20 余年的发展与建设, 已经形成了鲜明的地域特色和学科特色, 并于 2019 年入选国家级一 流本科专业建设点。近年来, 国内很多高校的应用化学专业对自身的建设都进行着积极的探索 ${ }^{[3-7]}$ 。

收稿: 2020-08-27; 录用: 2020-10-26; 网络发表: 2020-11-13

“通讯作者, Email: wgduan@gxu.edu.cn.

基金资助: 广西大学首批国家级一流本科专业建设项目 
为了契合当前高校培养具有创新精神的实践型、应用型专门人才的目标, 我校应用化学专业在专业 建设方面也进行了积极的探索与实践。

\section{1 找准专业定位, 突出特色优势}

国家教育规划纲要提出的三层次人才培养是学校确定办学定位的依据 ${ }^{[8]}$, 其中, “ 211 工程” 高 校和地方重点大学主要培养高水平、特色性应用型人才。广西大学作为广西唯一一所 “211工程” 高 校、“双一流”建设高校、“部区合建”高校，也应符合这个定位。

通过对十多个广西区内优秀化工和制药企业(如: 广西柳州化工股份有限公司、广西花红药业股 份有限公司、广西维尼纶集团有限责任公司、广西田园生化股份有限公司、广西明阳生化科技股份 有限公司、广西万寿堂药业有限公司等等)的调研, 普遍反映对化学类复合应用型人才有非常大的需 求。结合地方需求, 我校应用化学专业人才培养的理念是 “理工兼容, 重在应用”, 使学生具有坚 实的化学理论和实验基础, 同时与化学工程知识相结合, 兼具化学类与化工类人才的知识结构优势, 在开发能力、应用能力和创新能力等方面得到锻炼和提高, 造就专业宽、基础厚、能力强、有创新 精神和实践能力的新世纪的复合型高素质化学专业人才。人才培养目标符合广西大学建设高水平区 域特色研究型大学的定位。

天然有机化学和高分子化学是本专业的学科特色。广西具有十分丰富的天然优势生物质资源(如 海洋生物、药用植物、松脂、淀粉、橡胶、八角、肉桂等), 值得深入研究与开发利用。经过多年的 学科发展与积淀, 本专业教师在天然有机化学和高分子化学方面的研究取得了丰硕的科研成果, 拥 有 “有机化学” 广西重点学科, 以及 “广西高校应用化学技术与资源开发” 重点实验室。

依托学校办学特色和优势, 结合广西本地丰富的天然优势资源, 服务区域经济社会发展, 所设 置的特色课程彰显本专业的特色和优势, 使培养的学生具有特色和专长, 为学生未来的发展奠定较 好的专业基础。

\section{2 加强师资建设, 打造教学团队}

师资队伍的数量、结构、水平和教学投入是保障人才培养质量的关键 ${ }^{[9]}$ 。经过近些年学校大力 的人才引进, 本专业现有一支高学历、高职称、高水平、年富力强、思维敏锐、积极进取的学术队 伍。现有专任教师 30 人, 其中教授 17 人(二级教授 2 人)、副教授 10 人, 具有博士学位 28 人、留学归国 12 人。国家百千万人才工程国家级人选 1 人, 宝钢优秀教师奖获得者 3 人, 博士生导师 11 人, 硕士生 导师 28 人。

为了更好地保障本科教学质量, 全面开展教师教学能力提升培训。采取的措施主要有:

1) 坚持把师德师风作为教师素质评价的第一标准, 健全师德考核制度, 建立教师个人信用记录, 完善诚信承诺和失信惩戒机制, 推动师德建设常态化长效化。引导教师自觉按照习近平总书记提出 的 “四有好老师” 的标准, 做 “四个引路人”、做到 “四个相统一”, 引导学生做到 “四个正确认 识” ，推动 “思政育人” 与专业教育的有机融合，使专业课程与思想政治理论课同向同行，形成协 同效应。

2) 以授课经验丰富、教学水平高的教授为主导, 成立相应的教学团队, 每个教学团队定期进行 教学研究活动, 对教学进行总结和交流。观摩教学名师的教学过程, 与国内各高校的同行们进行教 学交流, 整体提高教学团队的教学水平。

3) 对于新入职的青年教师, 配备本专业教学经验丰富的教师作为其教学指导教师, 通过帮传带, 使其尽快胜任教学工作。 


\section{3 深化课程改革, 提高教学质量}

1) 以问题为导向, 以目标为引导, 持续修订培养方案, 创新培养模式, 提升培养目标的达成度。 通过2012、2015、2017版专业培养方案的修订, 课程体系设置得到越来越好的优化, 尽管总学分不 断压缩, 但始终坚持复合应用型人才的培养目标, 目前按照《普通高等学校本科专业类教学质量国 家标准》 ${ }^{[10]}$ 和学校自身办学实际和发展目标, 已完成2020版培养方案的修订工作。

2) 通过进一步调整课程体系, 建立以通用基础知识、工程实践与创新能力培养为主的课程体系。 在本专业开设的主干课程中, “四大化学” 均采用理科教学模式, 同时, 开设有化学工程基础、工 程制图、化学工艺学、化工安全与环保等工科课程。鼓励教师积极将本学科发展的前沿动态和最新 的科研成果融入教学内容。针对广西的天然优势资源和化学化工行业的需求情况, 开设纳米材料化 学、新型分离技术、天然有机化学、精细化学品化学、聚合物结构与性能等具有明显应用特色的课 程。围绕特色人才培养定位和培养要求, 通过增加相应专业课程、提高实验实践学时等措施来强化 学生开发和利用天然优势特色生物质资源的能力。

3) 以学生发展为中心, 通过教学改革促进学习变革, 积极推广小班化教学、混合式教学、翻转 课堂, 构建线上线下相结合的教学模式。充分利用慕课等优质资源平台, 鼓励教师多模式应用, 鼓 励学生多形式学习。因课制宜选择课堂教学方式方法, 科学设计课程考核内容和方式, 不断提高课 堂教学质量。积极引导学生自我管理、主动学习, 激发求知欲望, 提高学习效率, 提升自主学习能 力。

4) 提升课程难度, 严格过程考核, 加大过程考核成绩在课程总成绩中的比重。原有的课程考核 主要是: 期评成绩 $=$ 平时成绩 $30 \%+$ 期末考试成绩 $70 \%$, 由于期末考试所占比重大, 不少学生急功近 利, 不注重平时的学习和积累。为了突出对学生分析问题和解决问题的能力的考查, 加强创新意识 和学习能力的培养, 专业教师加强了对学生平时学习的过程考核, 采用课堂讨论、课程小论文、课 后作业、段考、期考等多种形式来科学地综合评价学生的学习效果。例如: 修订期评成绩为: 平时 (考勤、作业) $10 \%+$ 段考成绩 $20 \%+$ 课堂讨论 $10 \%+$ +课程小论文 $10 \%+$ 期末考试成绩 $50 \%$, 以充分调动学 生学习的积极性和主动性。

\section{4 注重实践环节, 培养创新能力}

实践性教学环节在培养学生动手能力、处理实际问题能力、创新能力等方面起到十分重要的作 用。

1) 本专业注重实践课程的开设, 四大化学基础实验课、仪器分析实验、应用化学综合实验均已 独立设课, 在国家标准的基础上, 加大化学实验教学学时, 并且综合性和研究性实验学时占比达到 $30 \%$ 。

2) 制定了完整的实习、实训、创新创业实践等集中实践环节, 形成了逐层推进、有机衔接、科 学合理的实践教学课程群。加强对毕业论文选题、开题、答辩等各环节的全过程管理, 严格控制一 人一题, 对形式、内容、难度、学术不端行为进行严格监控, 确保毕业论文质量。

3) 不断优化资源配置, 本科教学实验室面积和教学实验设备总值明显增长, 并将四大化学基础 实验教学与我校的 “国家级化学化工虚拟仿真实验教学中心” 有效衔接。加大实验教学改革的力度, 整合和优化实验内容, 增加综合性、设计性和开放性等 “三性” 实验在基础和专业实验教学中的比 例; 调整应用化学专业实验的教学内容, 增加难度和广度, 注意与广西优势资源及教师科研方向的 结合, 引入分析检测环节(如与波谱学和色谱学实验相融合)等。

4) 深入推行本科生导师制, 结合 “大学生创新创业训练计划”, 积极组织学生参加国家级学科 竞赛活动, 让学生早进实验室、早做科研, 增强学生的实验动手能力和创新能力。把导师制和创新 创业教育融入教学计划中, 鼓励教师开设导师课程, 将最新科研成果及时转化为教育教学内容, 以 高水平科学研究支撑高质量本科人才培养。 


\section{5 强化校企合作，建设育人平台}

完善协同育人机制、加强实践育人平台建设、强化科教协同育人。对人才培养进行协同管理, 培养真正适应经济社会发展需要的高素质专门人才。

1) 组建专业教学指导委员会: 聘请企业技术专家、工程技术人员, 与本专业带头人、骨干教师 共同组建专业教学指导委员会, 每年定期召开人才培养方案专题研讨会, 了解最新行业发展动态及 企业人才需求情况, 以教育部对本专业的规范为基本要求, 形成本专业的人才培养方案指导意见, 及时调整培养方案和专业课程。

2) 校企合作授课: 邀请企事业单位的工程技术人员到学校直接参与一些专业课程的授课, 如精 细化学品化学、化学工艺学、工业催化原理及应用、新型分离技术、仪器分析等课程, 使学生了解 和掌握最新行业发展动态、关键技术及装置、企业人才需求情况等, 为学生理解理论联系实际的重 要性创造条件。

3) 校企合导毕业论文: 在校内导师与企业导师共同指导下, 在企业完成本科毕业论文。根据毕 业论文选题, 同相关企业联合, 安排部分学生参与产品开发、科研项目研究等实践工作, 并完成毕 业论文的撰写, 使学生具备综合运用所学知识和技能分析与解决实际问题的能力, 初步形成融技术、 经济、市场、管理于一体的研发能力, 培养学生勇于探索的创新精神和实践能力, 以及严肃认真的 科学态度和严谨求实的工作作风。

4) 校企合建实习基地: 在广西柳化氯碱有限公司、广西梧州日成林产化工股份有限公司、广西 梧州松脂股份有限公司、广西田园生化股份有限公司等建立实习基地, 由企业兼职教师或工程技术 人员向学生讲解企业的概况、化学反应原理、工艺路线及流程、生产安全等事项后, 在其带领下, 结合生产设备了解反应特点、生产设备及流程; 参观主控室, 并根据工艺流程图, 熟悉化工企业的 生产流程, 了解安全生产的重要性。通过到企业实习, 使学生进一步巩固所学的专业理论知识, 培 养综合能力。

\section{6 完善质量保障, 促进持续改进}

为适应新时代对人才的多样化需求, 本专业注重专业质量保障体系建设, 提高学生和社会的满 意度。

1) 与时俱进, 根据学校自身办学实际和发展目标, 制定新版本科专业培养方案。根据新的培养 方案, 调整课堂教学内容, 定期更新教学大纲, 适时修订专业教材, 科学构建课程体系, 提高教学 质量。

2) 建立多元化、多层次的教学质量评价和监督机制, 建立了院系领导听课制度、学生评教制度、 教学督导制度, 开通系主任信箱, 设立学生教学信息员等。学校成立了教学督导团, 做到听课全覆 盖, 及时了解和处理教学中出现的问题。

3) 定期举行毕业生、用人单位意见征求活动, 吸纳行业、企业专家参与专业教学指导工作; 定 期开展专业自评, 及时发现和解决专业发展和建设过程中的问题。

\section{7 结语}

经过多年的专业建设, 我校应用化学本科专业取得了一定的成绩。但是, 目前的形势与建成一 流专业还存在一定的差距, 专业建设中的一些做法和措施也只是普遍做法, 没有形成很鲜明的特色。 针对自身的短板, 下一步推进专业建设和改革的主要思路是: 加强学科建设, 着重培养和引进学科 专业的领军人才, 注重学科带头人的建设, 组建高水平科研创新团队, 注重科研对教学的反哺。进 一步加强精品课程建设、教材建设、网络课程及慕课建设。推动学科-专业-课程一体化建设, 全面 提高教学质量, 从而为广西乃至全国培养和输送更多在天然有机化学和高分子化学领域具有高质量 的复合应用型化学人才。保持我校应用化学专业在广西高校中的领先地位, 并形成强势专业特色, 
为广西高校该专业的建设和改革起到带头作用。

专业建设是一项系统、持续的工程, 我们将脚踏实地, 立足地域优势资源, 以建设面向未来、 适应需求、引领发展、理念先进、保障有力的一流专业为目标, 不懈地探索和实践, 培养适应社会 需求的高素质、德智体美劳全面发展的复合型化学类创新人才。

参 考 文 献

[1] 教育部关于加快建设高水平本科教育全面提高人才培养能力的意见. [2018-10-08].

http://www.moe.gov.cn/srcsite/A08/s7056/201810/t20181017_351887.htm

[2] 王宇, 张兴文, 陈刚, 孙净雪. 大学化学, 2015, 30 (2), 26.

[3] 段文贵, 李斌, 韦万兴. 广西大学学报(哲学社会科学版), 2008, 30 (增刊), 66 .

[4] 唐冬雁, 李文旭, 强亮生. 中国大学教学, 2012, No. 1, 39.

[5] 曹小华, 严平, 徐常龙. 化学教育, 2014, No. 14, 10.

[6] 霍冀川, 雷洪, 梁晓峰, 叶旭. 中国大学教学, 2014, No. 11, 53.

[7] 张树永. 中国大学教学, 2014, No. 4, 48.

[8] 国家中长期教育改革和发展规划纲要(2010-2020年). [2010-07-29]. http://www.gov.cn/jrzg/2010-07/29/content_1667143.htm

[9] 张树永, 朱亚先. 中国大学教学, 2018, No. 3, 25.

[10] 教育部高等学校教学指导委员会. 普通高等学校本科专业类教学质量国家标准(上). 北京: 高等教育出版社, 2018: 3 . 